\title{
Educação do olhar e das sensibilidades pela leitura de imagens visuais nos livros didáticos de história
}

\author{
João Batista Gonçalves Bueno* \\ Maria de Fátima Guimarães** \\ Luzia Batista de Oliveira Silva ${ }^{* * *}$
}

\begin{abstract}
Resumo
Este artigo analisa as práticas de educação do olhar e das sensibilidades a partir do uso de imagens visuais impressas nos livros didáticos de ensino de História. Examinamos diferentes coleções desses manuais produzidos por variados autores e editoras e trabalhamos com edições distintas desses artefatos escolares contemporâneos. Entendemos que as imagens de patrimônios históricos reproduzidas para esses tipos de livros hierarquizam e legitimam a ideia de representação visual da beleza estética da arte e arquitetura clássica europeia e suas variações. Tomamos como pressuposto que as imagens impressas expressam determinadas informações relativas à ideia de patrimônio cultural ressaltando valores estéticos e simbólicos. Elas evidenciam esses tipos de significações, estimulando determinados gostos estéticos e o olhar que contribuem para o desenvolvimento da educação das sensibilidades. Discutimos, também, como a educação política dos sentidos pode nos instigar a refletir sobre os paradigmas da modernidade europeia, calcados nas ideias de civilização, progresso e modernização oriundas daquele continente. Além disso, procuramos compreender o porquê de o processo de leitura de imagens visuais no ensino de História ter ganhado grande relevância a partir dos anos finais da década de 1960 e início da década de 1970. Foi a partir desse processo que os livros didáticos passaram a apresentar uma grande quantidade de iconografias coloridas, o que possibilitou que fossem criadas novas perspectivas metodológicas em relação à exploração desses veículos de informação, que foram e são, ainda hoje, sacralizados na relação com as particularidades locais que tendem a ser desqualificadas e tidas, também, como precárias, modestas, atrasadas.

Palavras chave: Educação, livros de história, patrimônios culturais
\end{abstract}

\section{Education of the look and the sensibilities by the reading of visual images in the didactic books of history}

\begin{abstract}
This article analyzes the practices of education of the look and the sensibilities from the use of visual images printed in the textbooks of teaching of History. We have examined different collections of these manuals produced by various authors and publishers and have worked with distinct editions of these contemporary school artifacts. We understand that the historical heritage images reproduced for these types of books hierarchize and legitimize the idea of visual representation of the aesthetic beauty of European classical art and architecture and their variations. We assume that printed images express certain information about the idea of cultural heritage emphasizing aesthetic and symbolic values. They evidence these types of meanings, stimulating certain aesthetic and gaze tastes that contribute to the development of sensitivity education. We also discuss how the political education of the senses can instigate us to reflect on the paradigms of european modernity, based on the ideas of civilization, progress and modernization coming from that continent. In addition, we sought to understand why the process of reading visual images in the teaching of History gained great relevance from the late 1960s and early 1970s. It was from this process that the textbooks began to present a great number of colored iconographies, which allowed the creation of new methodological perspectives in relation to the exploitation of these information vehicles. These have been and still are sacralized in relation to local particularities, which tend to be disqualified, just as they are taken as precarious, modest, and backward.

Keywords: education, books of history, cultural patrimony
\end{abstract}

Analisam-se, neste artigo, algumas possibilidades de práticas de educação do olhar e das sensibilidades partindo de imagens visuais que representam patrimônios culturais e artísticos que

\footnotetext{
* Endereço Eletrônico: joaobgbueno@ hotmail.com

** Endereço Eletrônico: fatima.guimaraes@usf.edu.br

*** Endereço Eletrônico: lubaos@gmail.com
}

foram impressos em livros didáticos de História destinados aos alunos do ensino fundamental brasileiro. Partindo desse recorte temático, examinam-se diferentes coleções de livros didáticos 
de História, de variados autores e editoras e, também, algumas edições distintas desses artefatos escolares contemporâneos. Ao longo do desenvolvimento desta investigação, as percepções sensíveis e críticas foram sendo alteradas de acordo com as concepções e usos dessas imagens contidas nos livros didáticos de História desde os anos finais da década de 1990 até os dias de hoje.

Propusemos, inicialmente, que as imagens impressas nos livros didáticos expressavam determinadas informações relativas à ideia de patrimônio cultural, ressaltando-se tanto os valores estéticos como os simbólicos, mas, a partir dos anos finais da década de 1980, impulsionados pelas discussões e pela expansão do conceito de cultura, os conceitos de patrimônio cultural e artístico foram sendo ampliados, resultando na definição contemplada na Constituição Federal de 1988, no artigo 216.

Segundo esse artigo, os patrimônios culturais e artísticos são:

[...] os bens de natureza material e imaterial, tomados individualmente ou em conjunto, portadores de referencia à identidade, à ação, à memória dos diferentes grupos formadores da sociedade brasileira, nos quais se incluem:

I - As formas de expressão;

II - Os modos de criar, fazer e viver;

III - As criações científicas, artísticas e tecnológicas;

IV - As obras, objetos, documentos, edificações e demais espaços destinados às manifestações artístico-culturais;

$\mathrm{V}$ - Os conjuntos urbanos de sítios e valor histórico, paisagístico, artístico, arqueológico, paleontológico, ecológico e científico.

Nesse caso, é possível perceber que as imagens de patrimônios histórico reproduzidas nos livros didáticos de História hierarquizam e legitimam a ideia subjacente de uma representação visual da beleza estética da arte e da arquitetura clássica europeia e suas variações. Evidenciam, prioritariamente, os tipos de significações que levam ao estímulo de determinados gostos estéticos e de um olhar que contribuem para o desenvolvimento da educação das sensibilidades ao modo europeu. A tese de Valderamin (2000, p.77) contesta essa Educação dos Sentidos no processo de estetização brasileira europeizada, cuja ideia é "observar é progredir das percepções dos sentidos para a ideia, do concreto para o abstrato, dos sentidos para a inteligência, dos dados para o julgamento".
É inegável que as imagens visuais impressas nos livros didáticos de História estimulam, induzem, direcionam e podem promover uma educação estética. Essas imagens atestam a importância dos documentos históricos que estimulam a criação de memórias visuais nos estudantes, visto que a criação de memória, de acordo com Mate (2011), é fundamental por se constituir numa resistência ao tradicional da história, contribuindo para a fruição e o entendimento das informações que se relacionam com os bens culturais originais. Destarte, deve posicionar-se o historiador como aquele que lê a história com um olhar crítico para os aspectos éticos e estéticos no que se refere à tradição, com o objetivo de, no sentido benjaminiano, se pautar pela tradição "autêntica", que, segundo Mate (2011, p.151), é aquela:

...que tem em conta o momento de ruptura na transmissão, e não a tradição-convenção que se imagina a relação entre passado e presente como um continuum? Comecemos precisando o que entendemos por perigo: a ameaça à existência, seja pela aplicação de uma violência externa, seja pela interiorização do mecanismo opressor por parte da vítima. Essa violência ameaça o indivíduo singular, todo um povo, os conteúdos que se quer transmitir e a tradição que os transmite.

As leituras das imagens dos patrimônios culturais, de reproduções de obras de arte e dos textos didáticos, permitem aos estudantes iniciados a compreensão de que essas representações imagéticas expressaram determinados gostos, que elas produzem um padrão de beleza e representam as tradições da sociedade que produziu tais objetos. Dessa forma, quando os professores ensinam história por meio de imagens visuais, estimulam formas de olhar e raciocínios críticos que não são neutros.

Pesavento quando assevera-nos que a:

A percepção constrói um mundo qualificado através de valores, emoções, julgamentos. É capaz de produzir o sentimento, que é uma expressão sensível mais durável que a sensação, por ser mais contínua, que perdura mesmo sem a presença objetiva do estímulo. Assim, a sensibilidade consegue, pela evocação ou pelo rememorar de uma sensação, reproduzir a experiência do vivido, reconfigurado pela presença do sentimento (PESAVENTO, 2007, p. 13). 
Discute-se, neste texto, a fim de chamar a atenção para a possibilidade de superação de determinadas definições referentes aos processos de aprendizagem relativos à educação estética do olhar, o pressuposto de que ela - a aprendizagem ocorresse apenas nos momentos em que os indivíduos têm experiências diretas relacionadas aos objetos patrimoniais e artísticos originais, ou seja, os momentos de fruição da obra de arte e aquilo que a representa, ignorando que a sensibilização apenas pelo olhar direcionado ao objeto ao qual se refere, numa aula, por exemplo, pode ser um objeto conhecido de maneira livre pelo indivíduo, pode nunca ter sido problematizado no seu aprendizado da história. Por isso, Matozzi (2008) pontua que o trabalho educativo, a partir de uma imagem impressa no livro didático, não provoca nos estudantes um processo completo de compreensão e nem teria força suficiente para provocar num estudante do ensino fundamental, por exemplo, toda uma significação e interpretação de seu contexto social, histórico e político, porque para o autor, os estudantes necessitam vivenciar os espaços, os bens culturais a partir das seguintes condições:

A primeira condição é que as experiências de aprendizagem se desenvolvam com a utilização dos bens culturais originais: monumentos, arquiteturas, fontes de arquivo, peças de museus, sítios arqueológicos, quadros autênticos, etc. A segunda condição é que sejam objeto de observação e de uso para produzir informações. A terceira condição é que esses sejam colocados em relação com o contexto e com a instituição de tutela. A quarta condição que se promova a tomada de consciência de que são a minúscula parte de um conjunto muito mais amplo que permite o conhecimento do passado e do mundo, o prazer de conhecer, a fruição estética (MATOZZI, 2008, p. 2).

Certamente, o contato com os bens originais proporciona uma experiência ímpar, possibilitando ao estudante entender as informações e ter uma determinada compreensão dos atributos culturais relativos ao contexto em que foram configurados e constituídos os objetos a fim de interpretarmos os seus sentidos cultural, social, histórico, filosófico e político. Seguramente, o processo de sensibilização estética e a tomada de consciência crítica não ocorrem somente nesse momento, podem ter, por exemplo, início nas atividades didáticas que antecedem o espaço de ensino- aprendizagem na escola, em vez do contato do estudante com o objeto que é observado, que pode ser ou não posterior à problematização que se possa fazer dele. Por essa razão, quando as imagens visuais são problematizadas no processo de ensino de História, elas contribuem para o desenvolvimento de novas formas de olhar o mundo para melhor compreendêlo e agir sobre aquilo que fora dado, ao estudante, de modo fechado.

O processo de uso de leitura de imagens visuais no ensino de História ganhou relevância a partir do final dos anos de 1960 e início da década de 1970. (BUENO, 2011). Por essa razão, os livros didáticos passaram a apresentar grande quantidade de iconografias coloridas, permitindo, com isso, que fossem criadas novas perspectivas metodológicas em relação à exploração desses veículos de informação.

Essa leitura das imagens no espaço escolar pode complementar o conhecimento do passado que, para o historiador materialista, de acordo com Gagnebin (2011, p. 104),

...não é um fim em si. Porém, se a exatidão e a precisão históricas são imprescindíveis, é porque devem permitir ao historiador interromper, com conhecimento de causa, a história que hoje se conta, para inscrever nessa narrativa, que parece se desenvolver por si mesma, silêncio e fraturas eficazes.

Por isso, é fundamental desenvolver um estudo das reproduções das imagens pictóricas e dos patrimônios culturais que colocou-nos frente a possibilidades de trabalhar numa área de intercessão entre as disciplinas que estudam análises iconográficas. Assim, questões de fundamento estético e iconográfico são primordiais neste estudo, sendo componentes importantes mas, algumas vezes, não reconhecidos, da representação visual.

A palavra "leitura" remete-se à prática de ler os textos escritos. É um processo que compreende atividades diversificadas e que varia em relação às formas e aos objetivos da comunicação que o leitor pretende estabelecer. Por isso, é um ato complexo, historicamente datado, e que apresenta um caráter polivalente e provisório. Constrói-se pela relação do leitor com o texto escrito ou imagético, expressando, de maneira polissêmica, as possibilidades de compreensão das mensagens. Gibson e Levin (1985, p.438) entendem que $\mathrm{o}$ ato de ler se constitui num processo "adaptativo e flexível", podendo apresentar variações de acordo com os objetivos do leitor e as características formais e expressivas nos diferentes suportes de informação. 
Gagnebin (2007, p.85) lembra-nos de que, na tarefa da leitura da história, seja ela documentada ou através de imagens estéticas, deve-se considerar o processo dialético que, em Benjamin, tem a ver com o estudo em que:

....as imagens dialéticas devem ser distinguidas das imagens arcaicas; mas o sujeito histórico não as constrói; sua tarefa consiste muito mais em decifrá-las ou lê-las, em saber delas se aproveitar para transformar a constelação histórica. Esta descrição, em particular a metáfora da leitura, supõe um outro tipo de constituição da imagem dialética que pela atividade do sujeito racional.

Partindo desse pressuposto, quando utilizamos o termo "leitura de imagens" estamos reproduzindo e confirmando linhas de pensamento que acreditam na existência de algum tipo de equivalência entre as imagens visuais e a forma como funcionam as palavras.

A reflexão sobre os processos de leitura de imagens tem uma longa duração. Várias escolas teóricas - linguísticas, filosóficas, sociológicas, antropológicas, históricas e artísticas, entre outras já estudaram as práticas de leitura de imagens visuais. Os investigadores dessas áreas concordam nos seguintes pontos: as imagens visuais apresentam um caráter polissêmico e suscitam processos de análise realizados comparando-se os objetos reais com outras imagens ou com textos escritos.

Segundo Pereira $(2008$, p.1) todas as teorias produzidas a respeito do modo como ocorre a leitura de imagens partem de dois pressupostos:

Primeiro: A imagem pode ser entendida da mesma forma que um texto escrito. Nesse caso, compreende-se que a imagem visual apresenta características semelhantes aos signos linguísticos. Por isso, para realizar a interpretação das iconografias ${ }^{1}$, é necessário descobrir os seus constituintes mínimos, plano de expressão e plano de conteúdo, que são equivalentes aos signos representados pelas palavras (FLOCH, 1985), ou seja, a relação entre texto escrito e imagem visual permeia toda a reflexão sobre as formas possíveis de leitura.

Segundo: A leitura da imagem visual é diferente da leitura do texto escrito.

Francastel (2011) afirma que os mecanismos da linguagem (escrita) e da figuração (imagem) não se reduzem uns aos outros. Já Foucault (2000) entende que existem relações complexas entre as imagens visuais e os textos escritos, ou seja, elas apresentam regularidades intrínsecas e recíprocas pelas quais podemos definir redes conceituais que lhes são próprias. Assim, a linguagem - escrita ou falada - é diferente da imagem visual, pois o que vemos não é igual ao que dizemos ou escrevemos. Para Foucault,

O discurso não é, portanto, o fundo interpretativo comum a todos os fenômenos de uma cultura. Fazer aparecer uma forma não é uma maneira desviada (mais sutil ou mais ingênua, como se queira) de dizer alguma coisa. Naquilo que os homens fazem tudo não é, no fim das contas, um ruído decifrável. O discurso e a figura têm cada um, seu modo de ser; mas eles mantêm entre si relações complexas e embaralhadas. É seu funcionamento recíproco que se trata de descrever (FOUCAULT, 2000, p. 78).

Essas duas formas de compreensão de leitura de imagens visuais estão intrinsecamente ligadas. Quando o historiador Gaskell (1992) produziu o texto "História das Imagens", constatou que diferentes historiadores e pesquisadores de outras áreas de conhecimento já tinham utilizado imagens visuais para apresentar suas visões sobre o passado. Nesse caso, as imagens visuais já tinham servido como ilustrações de textos escritos e tinham como função enfeitá-los ou decorá-los; ou, ainda, elas eram utilizadas como forma de apresentar, visualmente, algum fato que estava sendo narrado pelo texto escrito. Constatou, ainda, que foi, a partir das concepções da escola dos Annales, nas primeiras décadas do século XX, que os historiadores, definitivamente, assumiram que as imagens visuais eram portadoras de uma função informativa original, passando, então, a ser encaradas como documentos históricos equivalentes aos textos escritos.

Gombrich (1999), ao desenvolver seus estudos sobre a Antiguidade Ocidental, indica que as imagens visuais serviram como sistema de comunicação antes do surgimento da escrita. Ao estudar as imagens produzidas na pré-história, reconhece que elas poderiam assumir um valor simbólico importante na vida das pessoas. Elas apresentavam uma faculdade afetiva, sendo tidas como amuletos de proteção ou representações de atos de magia. Exerciam, também, alguma força sobrenatural em rituais ou poderiam ser utilizadas para reverenciar a memória dos mortos. As imagens visuais eram, do mesmo modo, admiradas e expostas ao público ou, em muitos casos, 
conservadas em lugares fechados e protegidas das pessoas.

Desde os finais da década de 1960 e início da década de 1970, os livros didáticos brasileiros passaram a apresentar muitas imagens visuais. Apesar de todas as mudanças nas formas de abordagens históricas e educacionais que ocorreram nos livros didáticos, ao longo do século $\mathrm{XX}$, as coleções de imagens iconográficas que têm sido privilegiadas, praticamente, continuam as mesmas. Saliba (1997) as definiu como:

[...] imagens canônicas, que nos são impostos coercitivamente, daí também serem chamadas imagens coercivas. (...) Tais imagens constituem pontos de referência inconscientes, sendo, portanto, decisivas em seus efeitos subliminares de identificação coletiva. São imagens de tal forma incorporadas em nosso imaginário coletivo, que as identificamos rapidamente.

Quando começamos a desenvolver nossos estudos sobre as reproduções de imagens de patrimônios históricos e artísticos impressos nos livros didáticos de História, percebemos que a inserção de determinadas imagens que aparece, constantemente, nos manuais didáticos de história do Brasil, sacraliza-as como fontes iconográficas privilegiadas. Estas constituíram o acervo patrimonial e artístico nacional que passou a ser valorizado, até os dias de hoje, pela sociedade brasileira. Muitas dessas imagens, impressas nos livros didáticos de história, são constituídas por obras de arte acadêmicas produzidas no final do século XIX e início do século XX, obras arquitetônicas de estilo barroco, eclético ou modernista, e ainda, imagens das belezas naturais do Brasil.

Uma obra de arte, no sentido benjaminiano, nasce da disposição subjetiva de um autor. Metodologicamente, entretanto, ela não pode ser avaliada, apenas, pela subjetividade do crítico ou do observador, tampouco por uma análise de viés objetivo, por isso, a preocupação, neste artigo, de problematizar a questão da educação nas imagens visuais de obras de história e das sensibilidades do olhar as mesmas; uma educação estética para compreensão também da história ou da historiografia, que tem a ver ainda com a formação do sujeito leitor ou a importância da leitura da história graças às imagens visuais advindas da tradição histórica.

Como assinala Mate (2011), todo cuidado com as imagens ou com os documentos é pouco, dado que "vivemos numa cultura da amnésia e farão falta muitas energias para pensar a ética, e a política, o direito e a justiça, a verdade e a beleza a partir da memória dos vencidos" (p.167) e, no sentido adorniano, do "imperativo da memória", Mate pontua que "não se trata mais de levar em conta o desejo da história, mas de repensar a verdade, a bondade e a beleza a partir desse desejo" (p.166).

O uso de imagens canônicas nos livros didáticos explica-se por elas serem de domínio público, e isso barateia sua impressão. E, para além dessa questão técnica e comercial, existe também a manutenção das visões eurocêntricas nas concepções de História, presentes nos currículos escolares brasileiros desde o século XIX.

Nesse contexto, Benjamin chamou a atenção para o estudo da memória coletiva de Halbwachs que apontava para a necessidade de estudar a história coletiva e aberta, uma hermenêutica da história, dada a predileção do estudo da história na tradição. Todavia, "a história começa quando acaba a tradição" (HALBWACHS, cf MATE, 2011, p.157). Por isso, pensadores da memória, como Benjamin, se apresentam como historiadores de uma nova história em que se faz fundamental rememorar a história a fim de se fazer uma leitura anamnésica do passado esquecido ou ignorado, sensibilizar as novas gerações para adoção de um olhar estético sobre o passado e sobre a vida. E é por isso que permanecem, ainda nos dias hoje, no Brasil, especialmente, em 2017, as abordagens educacionais e históricas que ainda valorizam determinados gostos estéticos que privilegiam as relações dicotômicas entre povos civilizados e povos primitivos. Essas relações se expressam nas imagens impressas nos livros didáticos que apresentam as produções culturais produzidas por sujeitos de etnia branca de origem europeia como superiores e civilizadas, e as produções culturais de etnias indígenas e negras são ainda consideradas como fontes de origens primitivas. Notamos que os usos contínuos dessas reproduções iconográficas contribuem para a criação de processos educacionais que impõem, para os estudantes, as concepções do que deve ser considerado arte, do que é o Belo e do que são bens culturais ou patrimônios históricos.

É possível constatar essa relação, pela forma regular com que aparecem as reproduções dos quadros A Primeira Missa do Brasil (óleo/tela,1861) de Vitor Meirelles e a Independência ou Morte (óleo/tela,1888) de Pedro 
Américo, e capítulos de livros que descrevem a chegada dos portugueses para a "descoberta" do Brasil e, depois, as imagens heróicas da nossa independência de Portugal, legando ao esquecimento uma dívida pública do Brasil para a concessão da independência do Brasil colônia de Portugal. Não se pode esquecer que as cenas dos quadros, aqui citados, foram produzidas no final do século XIX e início do século XX e pertencem a um projeto da Escola de Belas Artes brasileira e reproduzem um estilo que prioriza o olhar naturalista, clássico europeu e uma estrutura que reproduz o olhar em perspectiva matemática e científica. Dessa forma, no processo educacional, essas imagens deveriam ser utilizadas com o devido cuidado para que os estudantes não as entendam como uma representação única e verdadeira dos fatos que ocorreram no Brasil.

A partir dessas considerações, faremos um breve levantamento das permanências e transformações relativas ao conceito do que que é a arte nos livros didáticos de História, procurando entender como essa concepção permanece quase inalterada desde o século XIX, no Brasil. Procuraremos, também, com esta análise problematizar questões da educação estética do olhar que buscam demonstrar que é possível existirem diferentes possibilidades de desenvolvimento de atividades didáticas partindo da expansão da concepção do que é a arte.

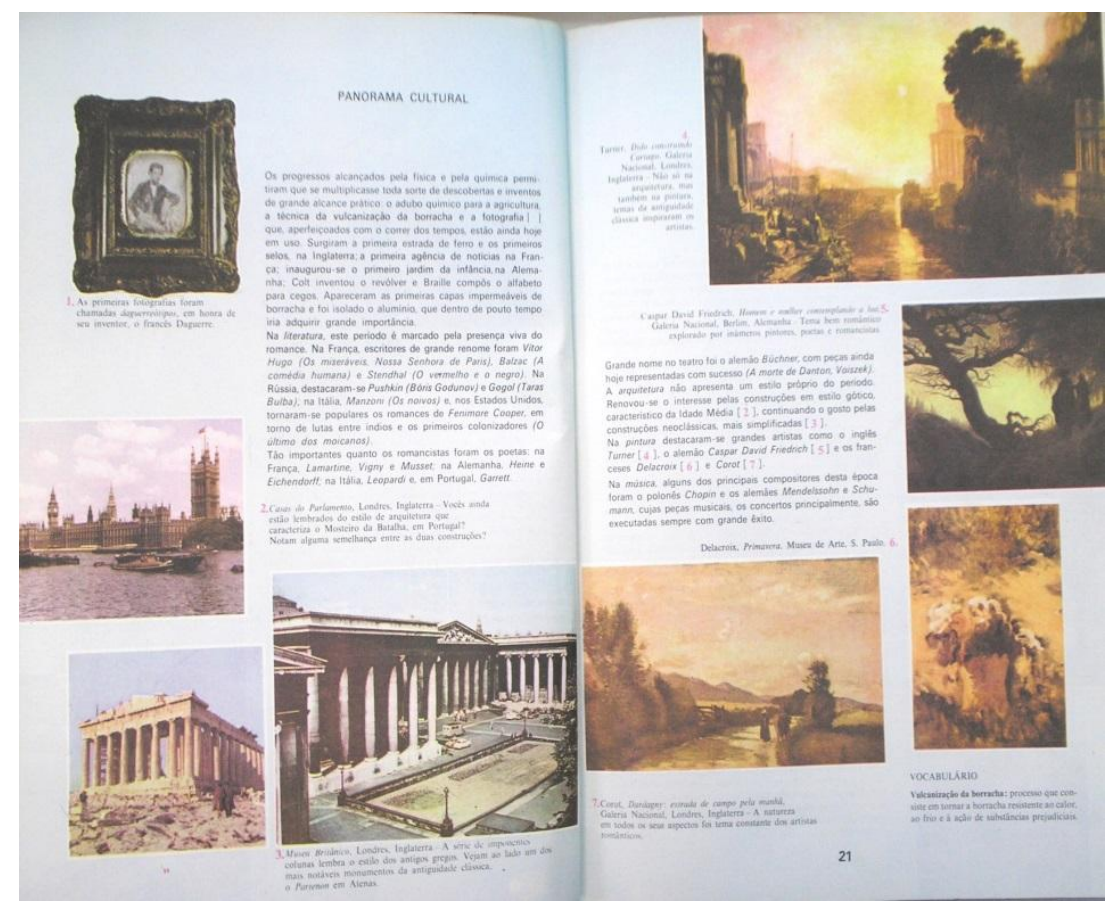

Figura 1 - Páginas 20 e 21 do livro de Sérgio Buarque de Holanda. História do Brasil -2- Estudos Sociais- Curso Moderno Da independência aos nossos dias - São Paulo: Companhia Editora Nacional- 1972. (19 X $26 \mathrm{~cm}$, cada página) (imagem reduzida).

Na coleção de Sergio Buarque de Holanda, editada a partir do ano de 1971, pode-se visualizar como esse autor apresentou os bens culturais e artísticos. No livro intitulado História do Brasil. Da independência aos nossos dias. Área de estudos sociais, de 1972, (Figura 1), nota-se como as imagens valorizam a ideia de patrimônio histórico e artístico, entendendo os elementos desse patrimônio como pertencentes à cultura erudita cuja origem é europeia. Nesse caso, os livros didáticos apresentavam as reproduções de obras de arte consagradas, de fotos e de edifícios arquitetônicos considerados de valor histórico.

Destarte, na coleção de Gilberto Cotrim e Álvaro Duarte de Alencar, editada em 1984, com o título: História Geral - para uma geração Consciente - Moderna e Contemporânea - Livro do Professor. (Figura 2), pode-se constatar a permanência da mesma ideia do que seja um patrimônio cultural e artístico, ainda que as imagens visuais selecionadas tenham sido outras. 


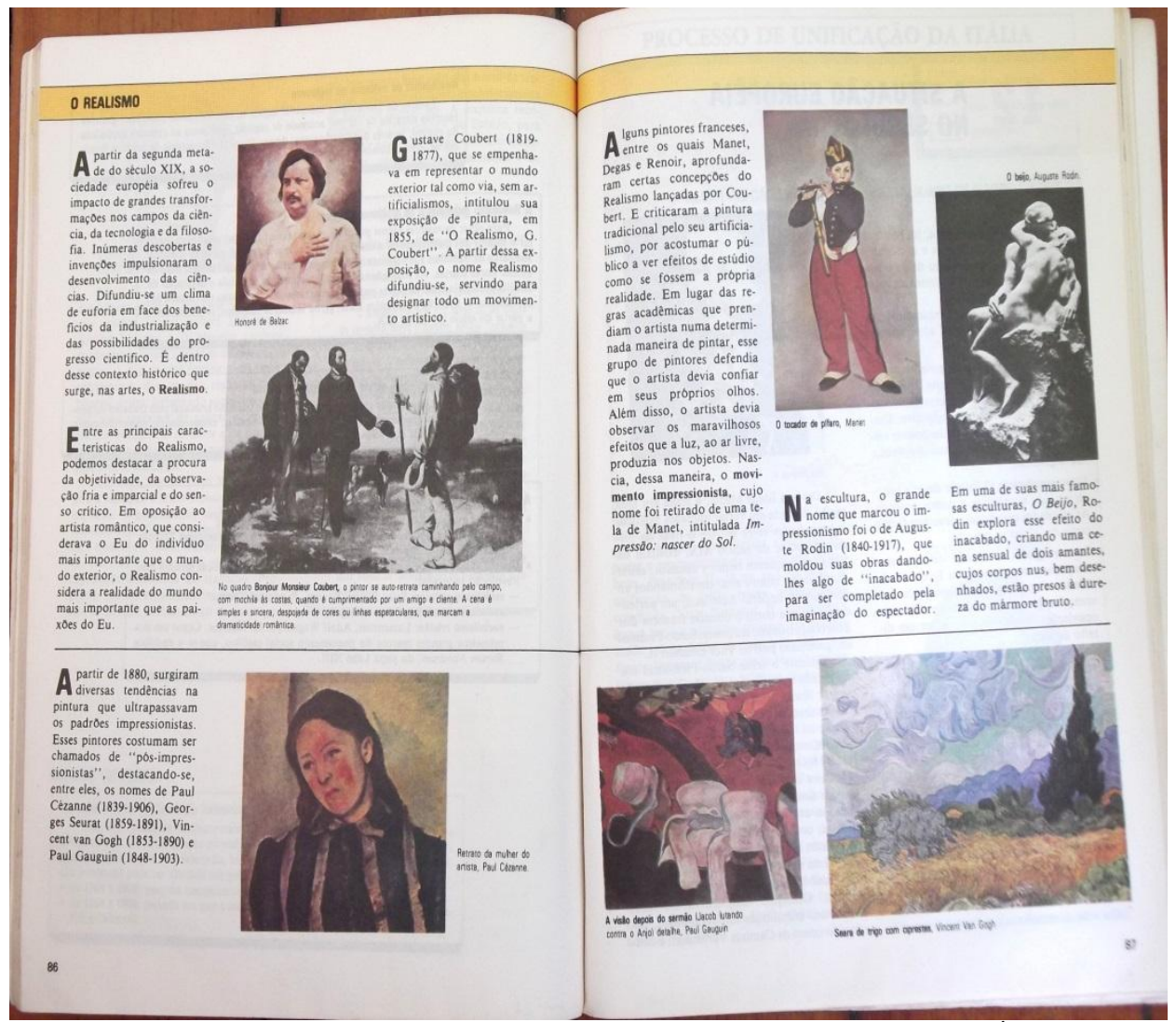

Figura 2 - Imagem das páginas 86 e 87, Imagens de obras de arte do livro de Gilberto Cotrim, Álvaro Duarte de Alencar. História Geral - para uma Geração Consciente. Moderna e Contemporânea. $8^{a}$ série. $1^{\circ}$ Grau. São Paulo: Saraiva, 1984 . (21 $\mathrm{X} 28 \mathrm{~cm}$, Imagem reduzida).

O objetivo desses materiais didáticos parece-nos simples: apresentar uma narração, permeada de textos escritos e imagens visuais, valorizando os fatos históricos ou os movimentos artísticos a partir de uma sequência de acontecimentos simbólicos. Essas imagens selecionadas eram impressas de forma que o estudante compreendesse que existia uma evolução dos objetos culturais e artísticos, valorizando, como afirmamos anteriormente, apenas os objetos que representavam a cultura erudita de origem e gosto europeus.

Outra forma de utilização das imagens visuais pode ser percebida pela criação de sequências narrativas, selecionadas de maneira a construir uma história da nação. Os textos didáticos, nesse caso, são fundamentados por um corpus de imagens de monumentos ou de retratos de indivíduos representando personagens das elites brasileiras que tinham poder sobre o Estado. Já as representações iconográficas dos objetos arquitetônicos que se destacam são as das igrejas barrocas de Minas Gerais, imagens da arquitetura neoclássica paulista ou do Rio de Janeiro, fotografias da cidade de Brasília e do Morro do
Corcovado, no Rio de Janeiro. Essas e outras imagens formam, portanto, um acervo iconográfico que foi sendo construído desde o século XIX e que procura dar a ideia de quais são os patrimônios culturais e artísticos que devem constituir o imaginário da nação brasileira. No que tange, especificamente à cidade do Rio de Janeiro, há muitas fontes que se ocupam de mostrar a França no Brasil através de seus monumentos arquitetônicos, de vestimentas de época, de canções e recriação de espaços como os de jardins, as praças e as calçadas que fazem também alusão à cultura europeizada.

Esperava-se, com esse tipo de montagem editorial/pedagógica, formar o cidadão pela instrução e pelo culto ao Estado - Nação (POLLOT, 2009, p.14), possibilitando, portanto, a criação de uma determinada identidade nacional e de uma educação cívica através de uma memória coletiva com fundo nacionalista.

Nos anos finais da década de 1980, foram feitas, nos estados, novas propostas curriculares de História, seguidas pelo lançamento dos PCNs no final da década de 1990. Essas novas propostas apresentavam uma ampliação do conceito de cultura, vindo das áreas de Antropologia, Sociologia 
e da História. Elas possibilitaram que os livros didáticos, a partir da década de 1990, no Brasil, apresentassem novas concepções referentes ao conceito de patrimônio cultural e artístico. Foi a partir daí, que a escola e as instituições culturais começaram a compreender que era necessário estudar outras culturas que estavam presentes na sociedade, mas que tinham sido excluídas ou ignoradas. Surgem, então, nos anos finais da década de 1990, novas discussões com o objetivo e preocupação de entender como as produções culturais das minorias étnico-sociais tinham também responsabilidade na criação dos bens formadores da nação.

A coleção de livros das autoras Sílvia Panazzo e Maria Luísa Vaz, Navegando pela História, editado em 2001 pela editora Quinteto Editorial, com quatro volumes destinados a alunos das $5^{\mathrm{a}}$ às $8^{\mathrm{a}}$ séries (hoje, do $6^{\circ}$ ao $9^{\circ}$ período) pode ser utilizada como forma de ilustrar a ampliação da concepção do conceito de cultura no ensino de história. Essa coleção possibilita que o leitor utilize as imagens visuais como forma de produção de novos conhecimentos, os quais podem se diferenciar das informações trazidas pelos textos explicativos apresentados nos capítulos.

A concepção de ensino de história apresentada nessa coleção prioriza abordagens que se aproximam das temáticas trabalhadas pela História social e pela História do cotidiano. As autoras questionam as visões tradicionais de ensino de história que valorizavam a concepção de tempo linear e cronológico. Apresentam atividades que procuram relacionar presente e passado e trabalham com contextos sociais, políticos, culturais e econômicos mais amplos.

Analisamos o capítulo 5 do livro, destinado às $5^{\mathrm{a}}$ séries $\left(6^{\circ}\right.$ ano, atualmente). Nesse capítulo, as autoras discutem o conceito de diversidade cultural, apresentando um texto escrito na relação com várias imagens visuais. Panazzo e Vaz (2001) trabalham esse conceito no texto explicativo, definindo-o como a forma que os seres humanos vivem e convivem entre si, a partir das suas necessidades e dos recursos de que as sociedades dispõem. O texto explicativo do livro afirma que foi nesse processo que as pessoas foram desenvolvendo "maneiras de morar, formar famílias, de trabalhar, de se comunicar, de manifestar a religiosidade, etc" ( $p$. 48).

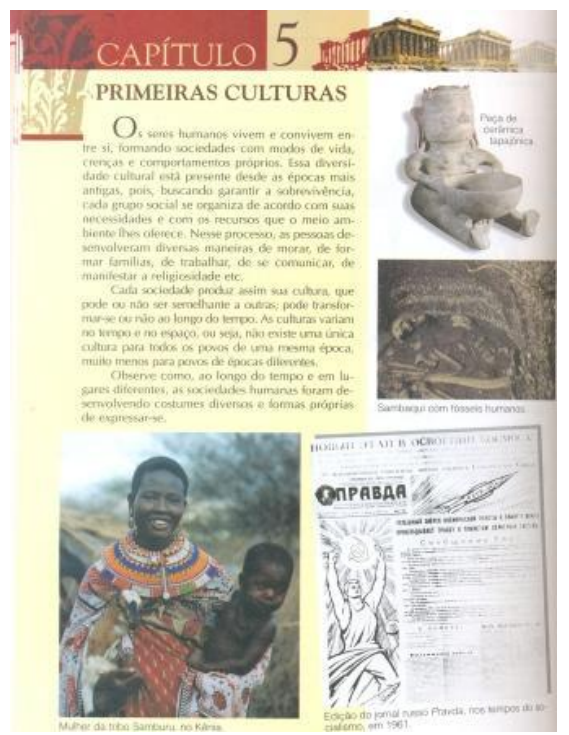

Figura 3 - Imagem da página 48 do livro de Silvia Panazzo e Maria Luísa Vaz, "Navegando pela História" editado em 2001 pelo Quinteto Editorial, São Paulo: Quinteto editorial, 2001, (21 X 28 cm, imagem reduzida).

É interessante perceber como as autoras apresentam diferentes objetos que representam atividades culturais produzidas em tempos distintos e pertencentes a variadas sociedades (Figura 3). Foram impressas, numa mesma página, a imagem de uma cerâmica marajoara, a imagem de um sambaqui, (ambas do Brasil), a imagem de uma mulher africana da tribo Samburu, do Quênia e uma página de um jornal russo dos tempos do socialismo, do ano de 1961. Ao identificar esses tipos de bens culturais, o professor pode trabalhar o conceito de que todas as marcas deixadas pelo homem na natureza são documentos históricos e que, portanto, são suportes de informações sobre o passado. Esses objetos podem também ser entendidos como patrimônios culturais materiais. 
No Brasil, esse tipo de concepção e o uso de imagens visuais ganharam mais espaço, visibilidade, após a promulgação da Lei $\mathrm{n}^{\circ}$ $10.639 / 03$ e da Lei $\mathrm{n}^{\circ} 11.645 / 2008$, que estabeleceram que os currículos de ensino da História e de outras disciplinas das escolas básicas passassem a contemplar os temas relativos estudo das culturas afro-brasileiras, africanas e indígenas. Também foi a partir dessas leis que o Estado lançou as Diretrizes Curriculares Nacionais para a Educação das Relações Étnico-Raciais.

Esse texto oficial trazia orientações aos professores das escolas básicas para que eles pudessem desenvolver ações educativas positivas que valorizassem os saberes, as experiências e as tradições das comunidades indígenas e negras. Esse documento teve, claramente, o objetivo de valorizar ações afirmativas étnico-raciais, compreendendo que o modelo de educação intercultural é produzido pelas relações horizontais entre as diferentes culturas, ou seja, elas não se dão por uma superposição ou uma hierarquização de uma cultura dominante sobre uma cultura subordinada, não sendo, portanto, o resultado da assimilação (pela cultura subordinada) dos valores, das práticas e os comportamentos da cultura dominante. Em consequência dessa concepção, o problema da educação étnico-racial e da criação de uma sensibilidade do olhar não é uma questão exclusiva das escolas indígenas e negras, mas, sim, de todos os segmentos da sociedade.

Sendo assim, propusemos, neste artigo, ir ao encontro de uma educação histórica e estéticopolítica dos sentidos que pudesse nos instigar a fim de refletirmos sobre os paradigmas da modernidade europeia, calcados nas ideias de civilização, progresso e modernização, oriundas daquele continente; paradigmas que foram e, ainda, são sacralizados na relação com as particularidades locais, que tendem a ser desqualificadas, tidas como precárias e modestas. Nesse contexto, recorremos a Mate $(2011$, p.154), que nos alerta para o fato de que "podemos entender agora por que a memória é perigosa e por que a história convencional não é".

\section{Notas}

1 Foi utilizado durante o desenvolvimento de todo o texto, o termo imagens visuais e seu sinônimo iconografias, visto que as sociedades modernas têm utilizado o significado da palavra imagem apenas para sua característica de evidência visual (ver para tal DEBORD, G., 2000) No entanto, é importante lembrarmos que a palavra "imagem" pode assumir diferentes conotações e sentidos. Segundo Aumont J.: "As imagens têm inúmeras atualizações potenciais, algumas se dirigem aos sentidos, outras unicamente ao intelecto, quando se fala do poder que certas palavras têm de "produzir imagem", por uso metafórico, por exemplo. Convém, portanto, dizer em primeiro lugar que, sem ignorar essa multiplicidade de sentidos, aqui só será considerada uma variedade de imagens, as que possuem forma visível, as imagens visuais" (2001.p. 8).

\section{Referências}

AUMONT, J. A Imagem. Trad. Estela dos Santos Abreu e Claudio Cesar Santoro. Campinas: Papirus, 2001, 159p.

BUENO, J. B. G. Imagens visuais nos livros didáticos: permanências e rupturas nas propostas de leitura (Brasil, décadas de 1970 a 2000). Tese de Doutorado, FE- UNICAMP, 2011.

DEBORD, G. A sociedade do espetáculo. Rio de Janeiro: Contraponto, 2000.

FOUCAULT, Michel. "As palavras e as imagens". Ditos e Escritos II. Rio de Janeiro: Forense Universitária, 2000, p. 78-81.

FRANCASTEL, P. Pintura e sociedade. São Paulo: Martins Fontes, 2011 (edição original 1951).

FLOCH, J.-M. Conceitos fundamentais de semiótica geral. In: FLOCH, Jean-Marie. Petites mythologies de l'oeil et de l'esprit. Amsterdam: Hadès-Benjamin, 1985, p. 189-207. Trad. Maria Lúcia Diniz. Bauru: UNESP, $1999 . \quad$ Disponível em: <http://www.faac.unesp.br/pesquisa/gescom/Textos/ Trad. $\% 20$ Foch\%20-

$\% 20$ Alguns $\% 20$ conceitos $\% 20$ fundamentais $\% 20 \mathrm{em}$ $\% 20$ semiotica\%20geral.pdf>.

Acesso em: 28 Fev./ 2017.

GAGNEBIN, J.-M. Divergências e Convergências sobre o Método Dialético entre Adorno e Benjamin. In: PUCCI, B. et al (Orgs.). Dialética Negativa, Estética e Educação. Campinas: Alínea, 2007, p.101-120. 
. História e narração em Walter Benjamin.

São Paulo: Perspectiva, 2011.

GASKELL, Ivan. História das imagens. In: BURKE, Peter (Org.). A escrita da História - Novas perspectivas. São Paulo: Unesp, 1992, p.237-272.

GIBSON, J.; LEVIN, H. General y Aplicada. The psychoígy of reading. Cambddge: MIT Press. $\mathrm{n}^{\circ}$ 38, 1985, p. 1116-1133.

GOMBRICH, E. H. A História da Arte. 16 ed. Trad. Álvaro Cabral. Rio de Janeiro: LTC, 1999.

MATE, R. Meia-noite na história: Comentários às teses de Walter Benjamin Sobre o conceito de história. Trad. Nélio Schneider. São Leopoldo: UNISINOS, 2011.

MATOZZI, I. Currículo de História e educação para o patrimônio. Educação em Revista, n 47, Belo Horizonte, jun./2008.

PEREIRA, V. Estética e imagem: onde reside a beleza? Revista científica. UNISUL, 2008, p. 1-20.
Disponível em: $<$ http://paginas.unisul.br/agcom/revistacientifica/arti gos_2008b/valdezia_pereira.pdf $>$. Acesso em: 13 fev./ 2017.

PESAVENTO, S. Cidades visíveis, cidades sensíveis, cidades imaginárias. Revista Brasileira de História. São Paulo, v. 27, $\mathrm{n}^{\circ}$ 53, jan-jun. 2007, p. 11-24.

POULOT, D. Uma história do patrimônio no Ocidente. São Paulo: Estação Liberdade, 2009.

SALIBA, E. T. As imagens canônicas e o ensino de história. In. SCHIMIDT, Maria Auxiliadora e CAINELLI, Marlene R. (Orgs.). III Encontro Perspectivas do Ensino de História. Curitiba: UFPR/Aos Quatro ventos, 1999.

VALDEMARIN, V. T. Lições de coisas concepção científica e projeto modernizador para a sociedade. Cadernos CEDES [online]. 2000, vol. 20, n 52, p. 74-87.

\section{Sobre os autores}

João Batista Gonçalves Bueno é Professor adjunto da Universidade Estadual da Paraíba, no curso de História. Membro efetivo do Programa de Pós-graduação em Formação de professores da Universidade Estadual da Paraíba. Membro efetivo do Programa de Pós-graduação em História da Universidade Federal da Paraíba. É doutor e mestre pela Faculdade de Educação da Universidade Estadual de Campinas, licenciado e bacharel em História pelo IFCH da Universidade Estadual de Campinas.

Maria de Fátima Guimarães é Professora adjunta e Coordenadora do Programa de Pós-Graduação Stricto Sensu em Educação da Universidade São Francisco. É doutora pela Faculdade de Educação da Universidade Estadual de Campinas, mestre em Ciência da Informação pela Pontifícia Universidade Católica de Campinas, bacharel e licenciada em História pelo IFCH da Universidade Estadual de Campinas.

Luzia Batista de Oliveira Silva é Professora do Programa de Pós-Graduação Stricto Sensu em Educação da Universidade São Francisco. É doutora em Educação pela Faculdade de Educação da Universidade de São Paulo, Mestre e bacharel em Filosofia pela Pontifícia Universidade Católica de São Paulo, Pós-doutorada em Antropologia pela Pontifícia Universidade Católica de São Paulo e Pós-doutorada em Filosofia pela Université de Bourgogne 2 Dijon/França.

Recebido em janeiro de 2017. Aprovado em março de 2017. 